Supporting information for

\title{
Efficient Screening of Glycan-Specific Aptamers Using a Glycosylated Peptide as a Scaffold
}

Wei Li, Yanyan Ma, Zhanchen Guo, Rongrong Xing, and Zhen Liu*

State Key Laboratory of Analytical Chemistry for Life Science, School of Chemistry and Chemical

Engineering, Nanjing University, Nanjing 210023, China

*Corresponding author: zhenliu@ nju.edu.cn

\section{Contents:}

- Supplementary Experimental Section

- Supplementary Figures

Figure S1 to Figure S13

- Supplementary Tables

Table S1 to Table S3

- Supplementary References 


\section{Supplementary Experimental Section}

Reagents. Adenosine, deoxyadenosine, trypsin, lactose, N-glycosidase F (PNGase F), horseradish peroxidase (HRP), bovine serum albumin (BSA), apo-transferrin human (TRF), ribonuclease A (RNase A), ribonuclease B (RNase B), fluorescein isothiocyanate isomer I (FITC), 2,4-difluoro-3formyl-phenylboronic acid (DFFPBA), trifluoroacetic acid (TFA) and $\alpha$-cyano-4hydroxycinnamic acid (CHCA) were obtained from Sigma-Aldrich (St. Louis, MO, USA). Sialic acid, 2-Iodoacetamide (IAA) and fucose were purchased from Aladdin (Shanghai, China). Mannobiose and mannopentaose were obtained from Yuanye Biotechnology (Shanghai, China). Amicon Ultra-0.5 (MWCO 3,000 Da) cartridges were purchased from Millipore (Billerica, MA, USA). Glutaraldehyde (GA, 25\% v/v) was purchased from Sinopharm Chemical Reagent (Shanghai, China). Tris-(2-carboxyethyl)-phosphine hydrochloride (TCEP), aminopropyltriethoxysilane (APTES), 3-ureidopropyltriethoxysilane (UPTES), isobutyltriethoxysilane (IBTES), tetraethyl orthosilicate (TEOS), galactose, maltose, 4formylphenylboronic acid (FPBA) and sodium cyanoborohydride were purchased from $\mathrm{J} \& \mathrm{~K}$ scientific (Shanghai, China). Ferric trichloride hexahydrate $\left(\mathrm{FeCl}_{3} \cdot 6 \mathrm{H}_{2} \mathrm{O}\right)$, ,, 6 -hexanediamine, anhydrous sodium acetate $(\mathrm{NaAc})$, glycol, ammonium bicarbonate $\left(\mathrm{NH}_{4} \mathrm{HCO}_{3}\right)$, sodium dihydrogen phosphate $\left(\mathrm{NaH}_{2} \mathrm{PO}_{4}\right)$, sodium hydroxide $(\mathrm{NaOH})$, hydrochloric acid $(\mathrm{HCl})$, acetic acid (HAc), sodium chloride $(\mathrm{NaCl})$, magnesium chloride $\left(\mathrm{MgCl}_{2}\right)$, potassium chloride $(\mathrm{KCl})$ and anhydrous ethanol were purchased from Nanjing Reagent Company (Nanjing, China). Methanol and acetonitrile (ACN) were purchased from Shanghai Macklin Biochemical (Shanghai, China). Ammonium hydroxide $\left(\mathrm{NH}_{3} \cdot \mathrm{H}_{2} \mathrm{O}, 28 \%\right)$ were purchased from Shanghai Lingfeng Chemical Reagent (Shanghai, China). Fru-CGLVPVLAE, CGLVPVLAENYNK and random test peptides (RTLHRNEYGIAS, KLTIESTPFNVA, LSGDVWDIDNEF, SSLLEACTFRR, SQPKIVKWDRDW) were synthesized by Top-Peptide Biotechnology (Shanghai, China), and their HPLC purities were above 98\%. All other reagents used were of analytical grade or higher. Water used in all the experiments was purified by a Milli-Q Advantage A10 water purification system (Millipore, Milford, MA, USA). 
The 66-nucleotide (nt) single-stranded (ss) DNA library consisted of a 25 nt central random region flanked by two constant sequences: 5'-FAM-CTT CTG CCC GCC TCC TTC C-N25-GGA GAC GAG ATA GGC GGA CAC T-3'. Such a library size has been reported as the theoretical minima to obtain full library diversity ( $4^{25}$ different species) and allow the formation of all secondary structures known for ssDNA oligonucleotides. ${ }^{1}$ The forward primer was 5 '-FAM-CTT CTG CCC GCC TCC TTC C-3' and the reverse primer was 5'-AGT GTC CGC CTA TCT CGT CTC C-3'. All DNA sequences were obtained from Sangon Biotech (Shanghai, China), and their unmodified, FAM-modified, and $\mathrm{NH}_{2}$-modified ssDNA sequences are listed in Table $\mathrm{S} 1$. TaKaRa $\mathrm{Taq}^{\mathrm{TM}}$ DNA Polymerase Hot Start Version was obtained from Takara Biotechnology (Dalian, China). The binding buffer solution contained $10 \mathrm{mM} \mathrm{NaH}_{2} \mathrm{PO}_{4}, 100 \mathrm{mM} \mathrm{NaCl}, 1 \mathrm{mM} \mathrm{MgCl}, 5$ $\mathrm{mM} \mathrm{KCl} \mathrm{(pH} \mathrm{7.4).} \mathrm{The} \mathrm{hepatocellular} \mathrm{carcinoma} \mathrm{HepG2} \mathrm{and} \mathrm{normal} \mathrm{liver} \mathrm{L02} \mathrm{cells,} \mathrm{phosphate}$ buffer solution for cell culture (1× PBS), parenzyme cell digestion solution (containing $0.25 \%$ trypase and 0.02\% EDTA), Dulbecco Modified Eagle Medium (DMEM, containing $4.5 \mathrm{mg} / \mathrm{mL}$ glucose, $80 \mathrm{U} / \mathrm{mL}$ penicillin and $0.08 \mathrm{mg} / \mathrm{mL}$ streptomycin) were purchased from Keygen Biotech (Nanjing, China). Fetal bovine serum (FBS) was purchased from Gibco (Life Technologies, Australia). Culture cells for cell culture and confocal imaging were purchased from NEST Biotech Corp (Wuxi, China).

Instruments. Transmission electron microscopic (TEM) characterization was carried out on a JEM-1011 system (JEOL, Tokyo, Japan). Fourier transform infrared (FT-IR) spectrometry was carried out on a Nicolet 6700 FT-IR spectrometer (Thermo Fisher, MA, USA). Matrix-assisted laser desorption/ionization time-of-flight mass spectrometric (MALDI-TOF MS) analyses were carried out on a 4800 plus MALDI TOF/TOF Analyzer (Applied Biosystems, Framingham, MA, USA) with a pulsed nitrogen laser operated at $337 \mathrm{~nm}$. All mass spectra reported were obtained in the positive ion and reflectron mode for peptide detection. A typical spectrum was obtained by averaging 3000 laser shots from 30 positions within the sample well. The accelerating voltage was $20 \mathrm{kV}$. The matrix for MALDI-TOF MS was $15 \mathrm{mg} / \mathrm{mL}$ CHCA dissolved in 50\% ACN containing 
$0.1 \%(\mathrm{v} / \mathrm{v})$ TFA. Equivalent amounts $(1 \mu \mathrm{L})$ of the sample and matrix were sequentially dropped onto the MALDI plate for MALDI-TOF MS analysis. Ultraviolent (UV) spectral analysis was performed with a NanoDrop 2000/2000C spectrophotometer (Thermo Fisher, MA, USA). Microplate reader analysis was carried out on a BioTek Synergy Mx microplate reader (Winooski, VT, USA). PCR amplification was implemented on a Biometra TOne PCR instrument (Analytikjena, Germany). Confocal fluorescence imaging of cells was acquired on a LSM 710 confocal laser scanning microscope (Zeiss, Germany).

\section{Preparation and characterization of boracic acid-functionalized magnetic nanoparticles (BA-} MNPs). BA-MNPs were synthesized according to a previously reported method by our group. ${ }^{2}$ The size and morphology were characterized by TEM. According to borate/cis-diol interactions, the selectivity was tested using adenosine (a cis-diol compound) and deoxyadenosine (a non cisdiol compound) as test compounds. An amount of $2 \mathrm{mg}$ BA-MNPs was dispersed into $200 \mu \mathrm{L}$ of 1 $\mathrm{mg} / \mathrm{mL}$ adenosine or deoxyadenosine in $\mathrm{NH}_{4} \mathrm{HCO}_{3}$ buffer $(50 \mathrm{mM}, \mathrm{pH} 8.5)$ containing $500 \mathrm{mM}$ $\mathrm{NaCl}$, then the mixture was shocked on a rotator at room temperature for $2 \mathrm{~h}$. The BA-MNPs were magnetically collected and rinsed with $200 \mu \mathrm{L}$ of $\mathrm{NH}_{4} \mathrm{HCO}_{3}$ buffer $(50 \mathrm{mM}$, pH 8.5) for three times. Finally, the BA-MNPs were resuspended and eluted in $50 \mu \mathrm{L}$ of $100 \mathrm{mM}$ HAc solution for $1 \mathrm{~h}$ on a rotator. The BA-MNPs were magnetically separated and the eluates were collected. The amount of adenosine or deoxyadenosine bound by the BA-MNPs were determined by measuring the absorbance at $260 \mathrm{~nm}$ of the eluates. To further investigate the selectivity of BA-MNPs, RNase A (a nonglycoprotein), RNase B (a glycoprotein), HRP (a glycoprotein) and BSA (a nonglycoprotein) were used as test compounds. The extraction procedure was the same as above except that the eluates were measured in terms of the absorbance at $214 \mathrm{~nm}$. The measurement was repeated for three times. For control experiments, all the procedures were the same as described above except the absence of target analytes in the extraction buffer. All experimental data were subtracted by the absorbance of the control group. 
Preparation of peptide-imprinted MNPs. Peptide-imprinted MNPs were prepared according to the approach reported previously called controllable oriented surface imprinting of boronate affinity-anchored epitopes ${ }^{2}$ with slight modifications. The preparation route is shown in Figure 2A, which was composed of following three steps:

Immobilization of template. Synthesized fructose modified peptide (Fru-CGLVPVLAE) was used as the template and immobilized onto boronic acid-functionalized magnetic nanoparticles (BAMNPs) by virtue of boronate affinity. An amount of $2 \mathrm{mg}$ fructose-modified peptide was dissolved in $2 \mathrm{~mL}$ of $\mathrm{NH}_{4} \mathrm{HCO}_{3}$ buffer ( $50 \mathrm{mM}$, pH 8.5) containing $500 \mathrm{mM} \mathrm{NaCl}$. Then $20 \mathrm{mg}$ of BA-MNPs were dispersed in $2 \mathrm{~mL}$ of the same buffer by ultrasonication, added into above peptide solution, and shaken at room temperature for $2 \mathrm{~h}$. The obtained peptide-immobilized BA-MNPs were collected by a magnet, and washed with $\mathrm{NH}_{4} \mathrm{HCO}_{3}$ buffer $(50 \mathrm{mM}$, pH 8.5) for three times.

Oriented imprinting. Multiple silylating reagents, including APTES, UPTES, IBTES and TEOS, that can offer different functionalities to interact with the template, were used to form a silica coating to cover the template to an appropriate thickness on the substrate surface. The above collected peptide-immobilized BA-MNPs were dispersed into $150 \mathrm{~mL}$ of anhydrous ethanol containing $4.5 \mathrm{~mL}$ of $\mathrm{NH}_{3} \cdot \mathrm{H}_{2} \mathrm{O}(28 \%)$, and $10 \mathrm{~mL}$ of water was added, the resulting suspension was mechanically stirred for $5 \mathrm{~min}$. Then different ratios of APTES, UPTES, IBTES and TEOS in $40 \mathrm{~mL}$ of anhydrous ethanol were added to the above suspension, and then the resulting solution was mechanically stirred at room temperature for $40,50,60$ or $70 \mathrm{~min}$. The obtained imprinted MNPs were collected by a magnet, washed with anhydrous ethanol for three times, and then dried at $40{ }^{\circ} \mathrm{C}$ in a vacuum oven overnight.

Removal of template. The obtained imprinted MNPs were dispersed into $2 \mathrm{~mL}$ of $\mathrm{ACN}: \mathrm{H}_{2} \mathrm{O}: \mathrm{HAc}$ $=50: 49: 1(\mathrm{v} / \mathrm{v})$ to disrupt noncovalent and boronate affinity interactions and shaken for $20 \mathrm{~min}$ at room temperature for three times. After removing the template, the prepared peptide-imprinted MNPs were magnetically collected, washed with water and anhydrous ethanol for three times each and then dried at $40{ }^{\circ} \mathrm{C}$ in a vacuum overnight. Non-imprinted MNPs were prepared using the same 
procedure except for the absence of template.

\section{Optimization of monomer composition and imprinting time for peptide-imprinted MNPs.}

The obtained peptide-imprinted MNPs can rebind the peptides that have the same terminal nine consecutive amino-acids as the imprinting template. In order to characterize the binding abilities of imprinted cavities, the synthesized nonmodified peptide CGLVPVLAENYNK was used as a test compound. The monomer composition and imprinting time for the preparation of peptideimprinted MNPs were optimized according to the parameter imprinting factor (IF), which was calculated according to the ratio of the amount of peptide captured by peptide-imprinted MNPs over that by non-imprinted MNPs. $2 \mathrm{mg}$ of imprinted and non-imprinted MNPs prepared with 4 different compositions of the monomers of APTES, UPTES, IBTES and TEOS for certain imprinting time were added to $200 \mu \mathrm{L}$ of $0.1 \mathrm{mg} / \mathrm{mL}$ nonmodified peptide dissolved in phosphate buffer (10 mM, pH 7.4), respectively. After incubation at room temperature for $20 \mathrm{~min}$, the MNPs were magnetically collected and rinsed with $200 \mu \mathrm{L}$ of phosphate buffer (10 mM, pH 7.4) for three times. The MNPs were re-suspended and eluted in $50 \mu \mathrm{L}$ of $\mathrm{ACN}: \mathrm{H}_{2} \mathrm{O}: \mathrm{HAc}=50: 49: 1$ (v/v) for 10 min on a rotator. Finally, the MNPs were magnetically separated and the eluates were collected. The amount of peptide was determined by measuring the amount of peptide in the eluates in terms of UV absorbance at $214 \mathrm{~nm}$. The measurement was repeated for three times. For control experiment, all the procedures were the same as described above except the absence of peptides in the extraction buffer. All experimental data were control-subtracted and averaged.

Selectivity test of peptide-imprinted MNPs at the peptide level. The selectivity of peptideimprinted MNPs was evaluated using various random peptides. First, $0.1 \mathrm{mg} / \mathrm{mL}$ each random peptide solution was separately prepared with phosphate buffer (10 mM, pH 7.4). Then equivalent imprinted and non-imprinted MNPs (2 mg each) were added to $200 \mu \mathrm{L}$ of the random peptide solutions, respectively. The tubes were shaken on a rotator at room temperature for $20 \mathrm{~min}$. The 
MNPs were magnetically collected and rinsed with $200 \mu \mathrm{L}$ of phosphate buffer (10 mM, pH 7.4) for three times. Second, the MNPs were re-suspended and eluted in $50 \mu \mathrm{L}$ of $\mathrm{ACN}: \mathrm{H}_{2} \mathrm{O}: \mathrm{HAc}=$ 50:49:1 (v/v) for $10 \mathrm{~min}$ on a rotator. Finally, the MNPs were magnetically separated and the eluates were collected. The amount of peptide was determined by measuring the UV absorbance at $214 \mathrm{~nm}$. The measurement was repeated for three times. For control experiment, all the procedures were the same as described above except the absence of peptides in the extraction buffer. All experimental data were control-subtracted and averaged.

Digestion of TRF by trypsin. The procedure for the tryptic digestion of TRF was as follows: 1 $\mathrm{mg} / \mathrm{mL}$ of protein was dissolved in $\mathrm{NH}_{4} \mathrm{HCO}_{3}$ buffer $(50 \mathrm{mM}, \mathrm{pH} 8.5)$, TCEP was added to be 10 $\mathrm{mM}$ in solution, and heated in a water bath of $95{ }^{\circ} \mathrm{C}$ for 5 min with frequent shaking. After the protein solution was cooled to room temperature, IAA was added to be $20 \mathrm{mM}$ in solution, and reacted for 50 minutes in darkroom, trypsin was added to the above tube at $37^{\circ} \mathrm{C}$ for $18 \mathrm{~h}(50: 1$, w/w). Finally, the resulting mixture was heated again to $95^{\circ} \mathrm{C}$ for $10 \mathrm{~min}$. The obtained protein digest solution was stored at $-20{ }^{\circ} \mathrm{C}$.

Desialylation of glycopeptides. To effectively improve the MS detectability of sialylated peptides, sialic acids of the glycopeptides of TRF were removed by acidic hydrolysis. $90 \mu \mathrm{L}$ of $0.05 \mathrm{M} \mathrm{HCl}$ was added to $10 \mu \mathrm{L}$ of the glycopeptides to be hydrolyzed in a $0.5-\mathrm{mL}$ Eppendorf tube and the mixture was incubated at $80{ }^{\circ} \mathrm{C}$ for $60 \mathrm{~min}$ with frequent shaking. Upon completion of the hydrolysis reaction, the contents were lyophilized and redissoved in phosphate buffer $(10 \mathrm{mM}, \mathrm{pH}$ 7.4).

Deglycosylation of glycoprotein. Standard glycoprotein with concentration of $1 \mathrm{mg} / \mathrm{mL}$ was prepared with phosphate buffer $(10 \mathrm{mM}, \mathrm{pH} 7.4)$. The protein solution $(100 \mu \mathrm{L})$ was boiled for 10 
min, cooled to room temperature, added with $10 \mathrm{U}$ of PNGase $\mathrm{F}$ and then incubated at $37{ }^{\circ} \mathrm{C}$ for $24 \mathrm{~h}$. Finally, the glycans in the mixture were isolated by the Amicon Ultra- 0.5 ultrafiltration cartridge at 14,000 $\mathrm{rpm} / \mathrm{min}$ for $30 \mathrm{~min}$. Then the filtrate fraction (glycans) in the microcentrifuge tube was collected by pipette. To collect the retentate fraction (deglycosylated proteins) remaining on the ultrafiltration cartridge, place the ultrafiltration cartridge upside down in a clean microcentrifuge tube and centrifuge it at 1,000 rpm/min for $2 \mathrm{~min}$. The retentate fraction transferred to the microcentrifuge tube was collected by pipette. All fractions were stored at $-20{ }^{\circ} \mathrm{C}$ for future use.

\section{Characterization of the desired glycosylated peptide from TRF digestion extracted by} peptide-imprinted MNPs. First, equivalent peptide-imprinted and non-imprinted MNPs (2 mg each) were added to $1 \mathrm{~mL}$ of TRF tryptic digestion $(1.0 \mathrm{mg} / \mathrm{mL})$ solution in $1.5-\mathrm{mL}$ centrifugal tubes, respectively. The tubes were shaken on a rotator at room temperature for $2 \mathrm{~h}$. The MNPs were magnetically collected and rinsed with $1 \mathrm{~mL}$ of phosphate buffer $(10 \mathrm{mM}, \mathrm{pH} 7.4)$ for three times. Second, the MNPs were re-suspended and eluted in $20 \mu \mathrm{L}$ of ACN:H${ }_{2} \mathrm{O}: \mathrm{HAc}=50: 49: 1$ (v/v) for $1 \mathrm{~h}$ on a rotator. Finally, the MNPs were magnetically separated and the eluates were collected. The eluates were desialylated and analyzed by MALDI-TOF MS.

DNA elution from the beads under varied conditions. A 2-mg amount of peptide-imprinted MNPs was mixed with $40 \mu \mathrm{L}$ nonglycopeptide CGLVPVLAENYNK $(1 \mathrm{mg} / \mathrm{mL})$ solution and incubated at room temperature on a rotator for $2 \mathrm{~h}$. After magnetic separation, the complexes were washed with binding buffer for three times, and nonglycopeptide-bound imprinted MNPs were subsequently collected by magnetic separation. 300 pmol initial FAM-ssDNA library dissolved in $100 \mu \mathrm{L}$ binding buffer was heated at $95^{\circ} \mathrm{C}$ for $10 \mathrm{~min}$ and then quickly cooled on ice for $10 \mathrm{~min}$, the obtained nonglycopeptide-bound imprinted MNPs was added and shocked on a rotator at room temperature for $1 \mathrm{~h}$. After magnetic separation, the supernatant and washed solution were collected 
(unbound ssDNA), and two strategies were respectively applied to elute the bound ssDNA from magnetic nanoparticles. (1) The $100 \mu \mathrm{L}$ binding buffer was added into the particles collected. The tube was heated in a water bath of $95{ }^{\circ} \mathrm{C}$ for $15 \mathrm{~min}$, the elution solution was collected. (2) $100 \mu \mathrm{L}$ of 0.1 M HAc solution was added into the tube, and then incubated with rotation at room temperature for $30 \mathrm{~min}$. After incubation, the elution solution was collected. The fluorescence of unbound and eluted bound fraction was detected by a microplate reader, with emission signal in $520 \mathrm{~nm}$ and $488 \mathrm{~nm}$ excitation. The fluorescence intensity was transformed into DNA concentration by referring to an external calibration. For control experiments, all the procedures were the same as described above except the absence of ssDNA. All the measurements for each condition were repeated for three times and the data were control-subtracted. Elution efficiency was calculated as following Equation S1:

$$
\text { Elution efficiency }(\%)=\frac{n(\text { eluted bound ssDNA })}{n \text { (initial ssDNA) }-\mathrm{n}(\text { unbound ssDNA })} \times 100 \%
$$

Nonspecific adsorption of ssDNA on different MNPs. 300 pmol initial FAM-ssDNA library dissolved in $100 \mu \mathrm{L}$ binding buffer was heated at $95{ }^{\circ} \mathrm{C}$ for $10 \mathrm{~min}$ and then quickly cooled on ice for $10 \mathrm{~min}$. And then the solution was incubated with $2 \mathrm{mg}$ BA-MNPs, imprinted MNPs and nonimprinted MNPs respectively, and shocked on a rotator at room temperature for $1 \mathrm{~h}$, followed by rinsing with $100 \mu \mathrm{L}$ binding buffer three times. Finally, the MNPs were re-suspended in $100 \mu \mathrm{L}$ binding buffer and eluted by heating at $95{ }^{\circ} \mathrm{C}$ for $15 \mathrm{~min}$. The MNPs were magnetically separated and the eluates were collected. The fluorescence of eluted solutions was detected by a microplate reader. For control experiment, all the procedures were the same as described above except the absence of ssDNA. All the measurements for each condition were repeated three times and the data were control-subtracted.

Monitoring the enrichment process in the SELEX rounds. After ten rounds of selection, the 
enrichment level at each round was evaluated. In order to monitor the enrichment progress of specific ssDNA throughout the selection, the binding affinity of each round ssDNA pool toward positive and negative targets was measured by fluorescence method. Equivalent (300 pmol) initial FAM-ssDNA library and FAM-ssDNA pool at each round dissolved in $100 \mu \mathrm{L}$ binding buffer were heated at $95{ }^{\circ} \mathrm{C}$ for $10 \mathrm{~min}$ and then quickly cooled on ice for $10 \mathrm{~min} .2 \mathrm{mg}$ obtained glycopeptidebound imprinted MNPs and nonglycopeptide-bound imprinted MNPs were added respectively and incubated at room temperature for $1 \mathrm{~h}$ on a rotary shaker. After magnetic separation, the supernatant was removed and the particles were washed with binding buffer for three times. The bound ssDNA was eluted by heating at $95{ }^{\circ} \mathrm{C}$ for $15 \mathrm{~min}$ with $100 \mu \mathrm{L}$ binding buffer. Through magnetic separation, the eluate was collected and the fluorescence was detected by a microplate reader. For control experiment, all the procedures were the same as described above except the absence of ssDNA. All the measurements for each condition were repeated three times and the data were controlsubtracted.

PCR amplification, cloning and sequencing. Eluates of each round were amplified by asymmetry PCR using an excess FAM-forward primer and limited reverse primer. PCR process included $95{ }^{\circ} \mathrm{C}$ for $5 \mathrm{~min}$, then 25 cycles of $94{ }^{\circ} \mathrm{C}$ for $1.5 \mathrm{~min}, 56^{\circ} \mathrm{C}$ for $0.5 \mathrm{~min}$, and $72{ }^{\circ} \mathrm{C}$ for $1.5 \mathrm{~min}$, ended by $10 \mathrm{~min}$ at $72{ }^{\circ} \mathrm{C}$. While for saturated round product, the selected aptamers were amplified by symmetry PCR with non-modified forward primer and sent for cloning, 100 clones were chosen randomly for sequencing at the Sangon Biotech (Shanghai, China). The secondary structures were analyzed with the on-line software IDT (http://sg.idtdna.com/calc/analyzer). 


\section{Supplementary Figures}

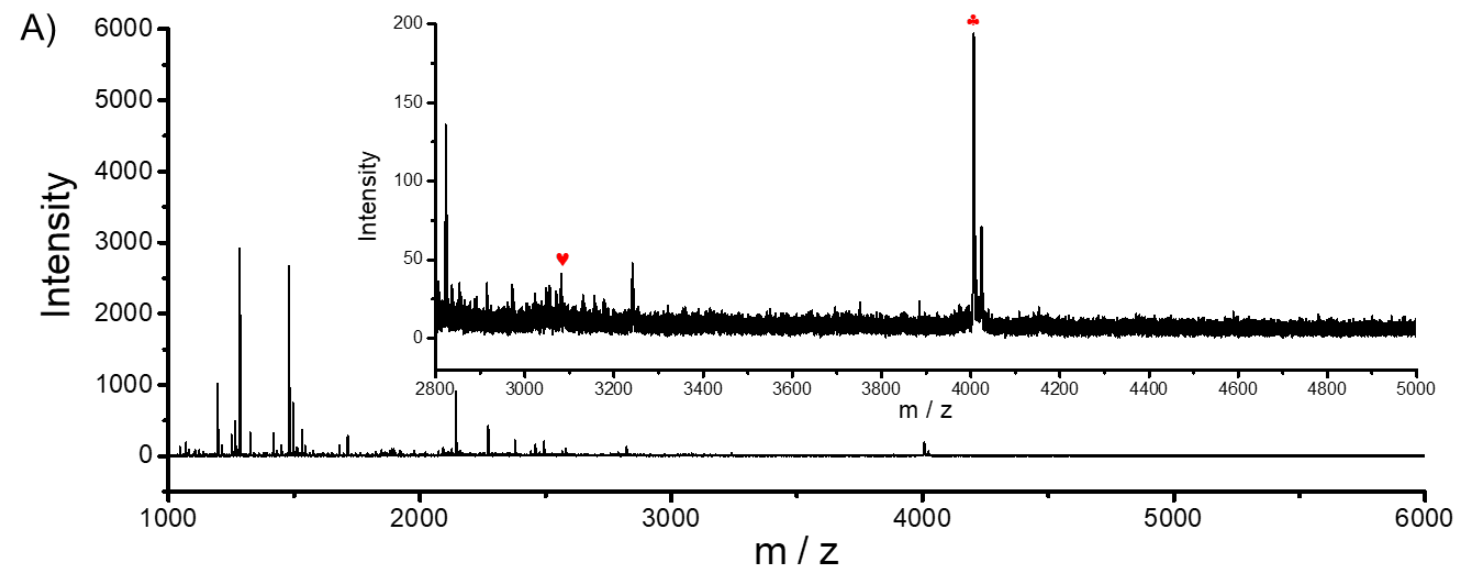

B)

\begin{tabular}{ccc|c}
\hline Symbol & $\mathbf{m} / \mathbf{z}$ & Sequence & Glycans \\
\hline $\boldsymbol{v}$ & 3082 & CGLVPVLAENYN\#K & $\mathrm{Gal}_{2} \mathrm{Man}_{3} \mathrm{GlcNAc}_{4}$ \\
\hline & 4006 & QQQHLFGSN\#VTDCSGNFCLFR & $\mathrm{Gal}_{2} \mathrm{Man}_{3} \mathrm{GlcNAc}_{4}$ \\
\hline
\end{tabular}

Figure S1. A) MALDI-TOF MS spectra for the analysis of TRF tryptic digest after desialylation. B) Detailed information of two TRF tryptic glycopeptides, and the glycopeptide marked with red heart symbol was chosen as the desired target for positive selection. 
A)

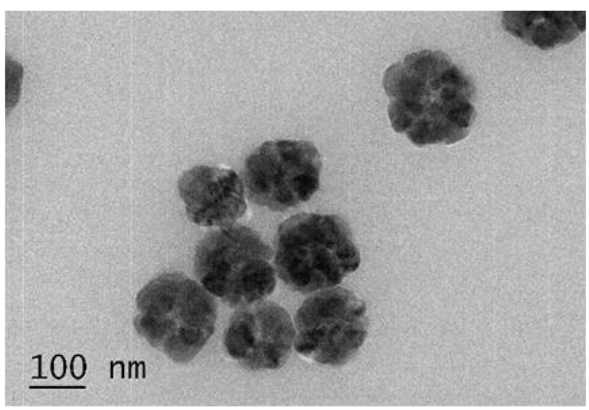

C)

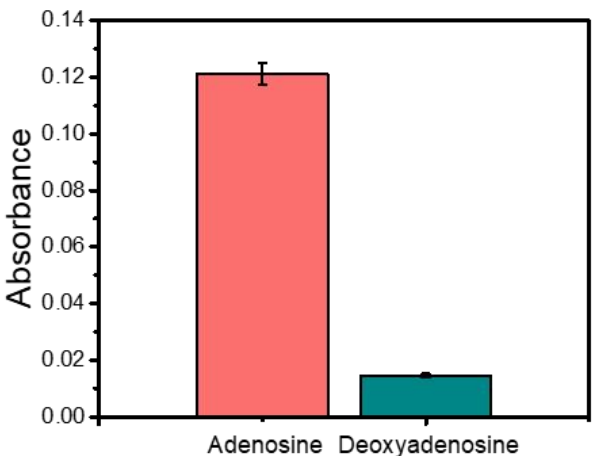

B)

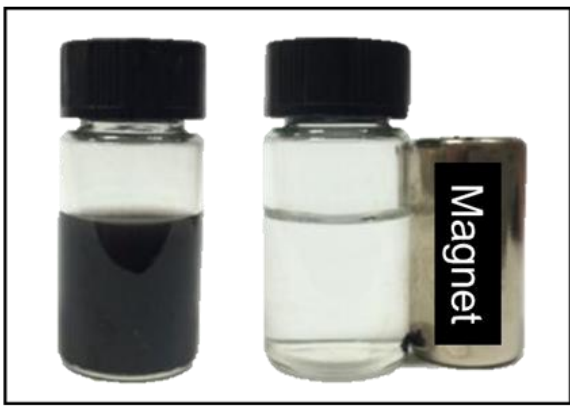

D)

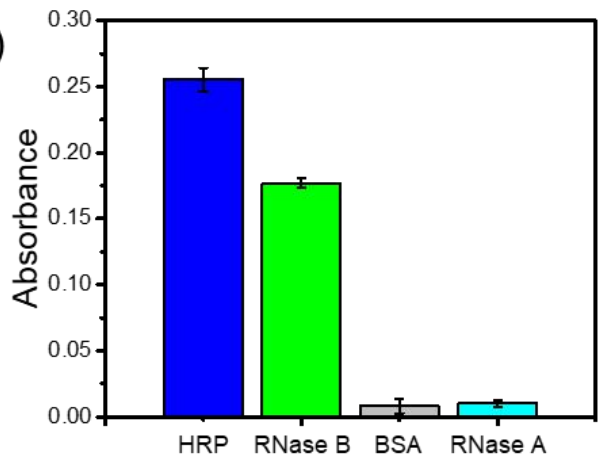

Figure S2. Characterization of BA-MNPs. A) Transmission electron microscopic (TEM) image. B) A photograph showing dispersion and magnetic separation of BA-MNPs. C) Selectivity of BAMNPs towards adenosine or deoxyadenosine. D) Selectivity of BA-MNPs towards glycoproteins or non-glycoproteins. Error bars represent standard deviations for three parallel measurements. 
<smiles>CCO[Si](CCCN)(OCC)OCC</smiles>

APTES

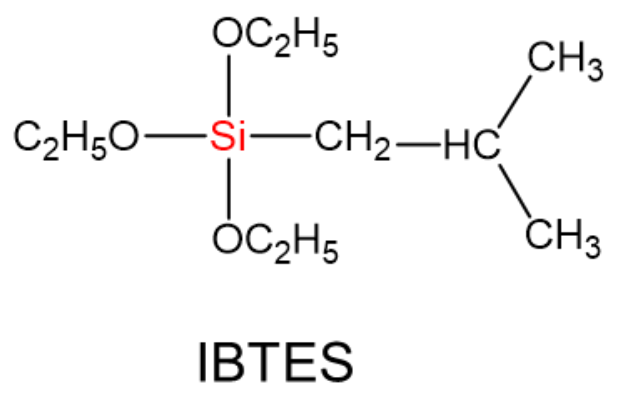<smiles>CCO[Si](CCCNC(N)=O)(OCC)OCC</smiles>

UPTES<smiles>CCO[Si](OCC)(OCC)OCC</smiles>

TEOS

Figure S3. Structures of the silylating monomers used in this study. 


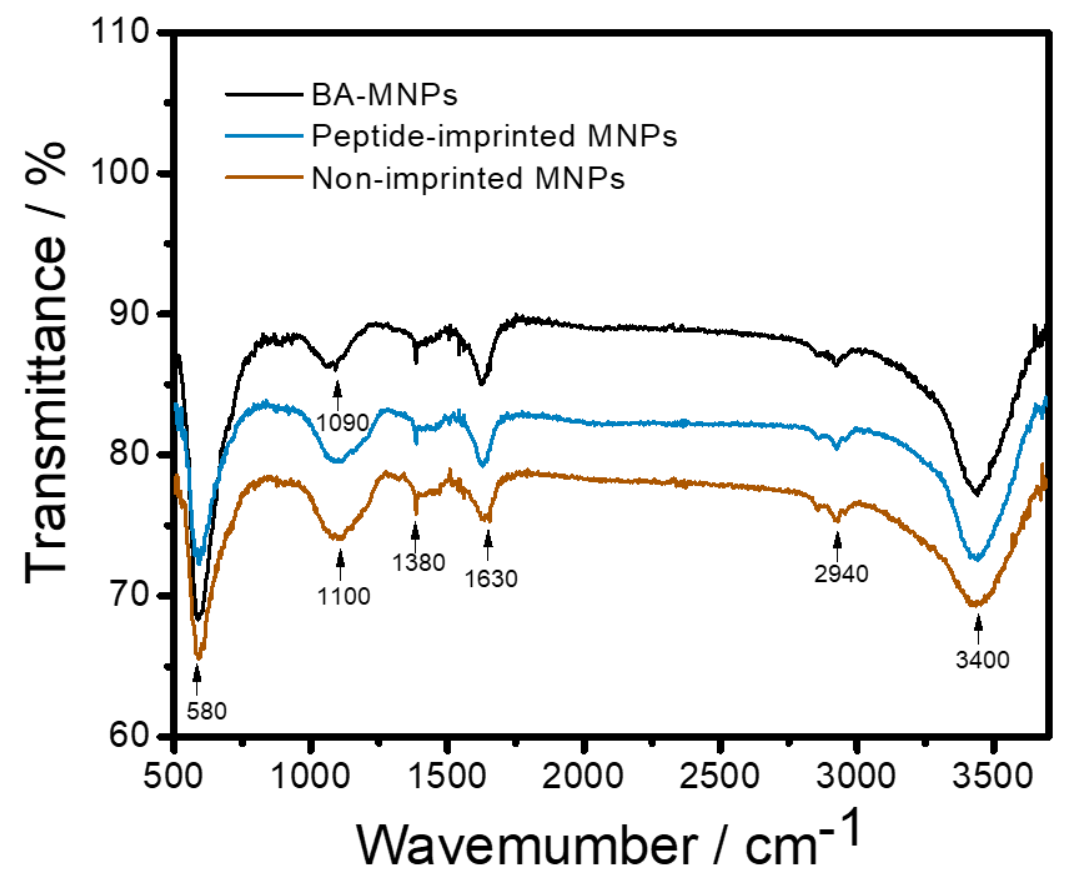

Figure S4. FI-IR spectra for BA-MNPs, peptide-imprinted MNPs and non-imprinted MNPs. The absorption peaks at $580 \mathrm{~cm}^{-1}, 1090 \mathrm{~cm}^{-1}, 1100 \mathrm{~cm}^{-1}, 1380 \mathrm{~cm}^{-1}, 1630 \mathrm{~cm}^{-1}, 2940 \mathrm{~cm}^{-1}$ and $3400 \mathrm{~cm}^{-}$ ${ }^{1}$ are attributed to $\mathrm{Fe}-\mathrm{O}, \mathrm{C}-\mathrm{F}, \mathrm{Si}-\mathrm{O}, \mathrm{C}-\mathrm{H}, \mathrm{C}=\mathrm{O}, \mathrm{C}-\mathrm{H}$ and $\mathrm{N}-\mathrm{H}$ vibration, respectively. 


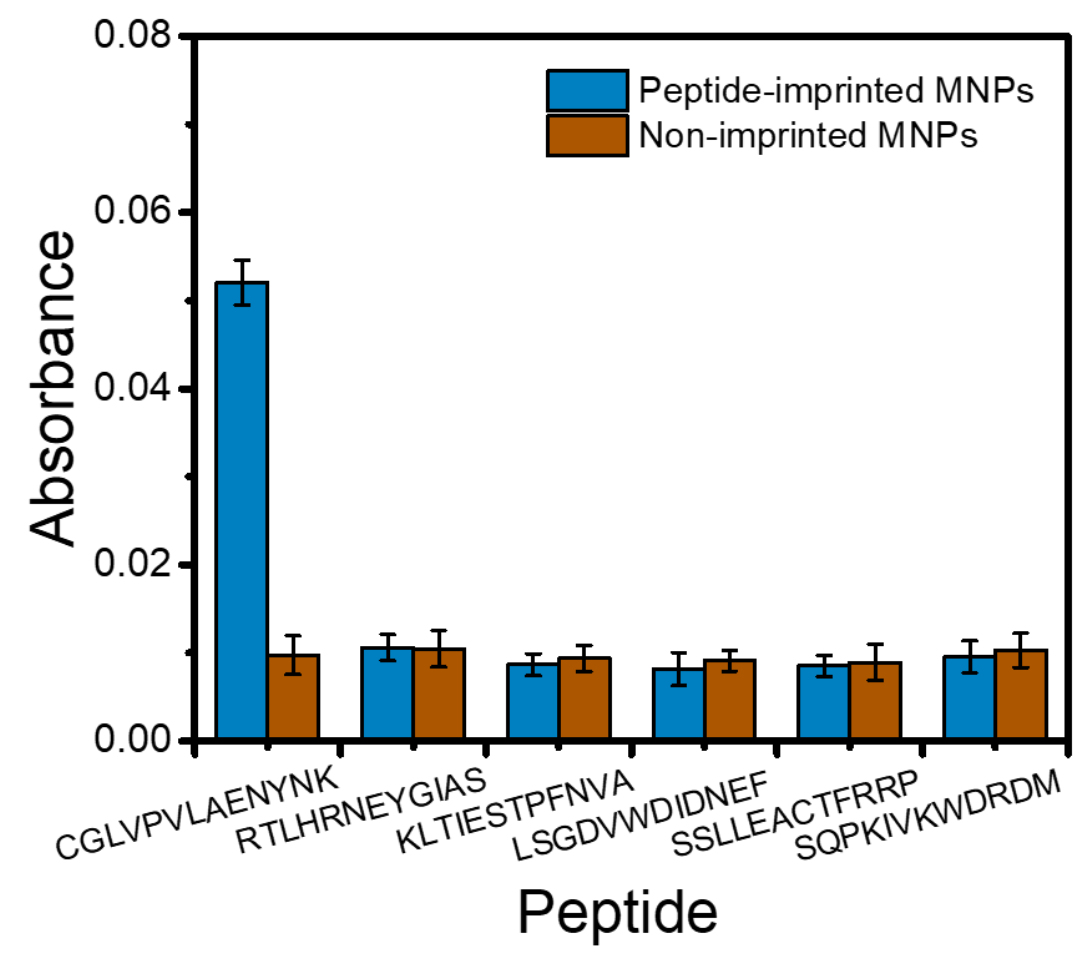

Figure S5. Selectivity of peptide-imprinted MNPs towards different peptides. Error bars represent standard deviations for three parallel measurements. 

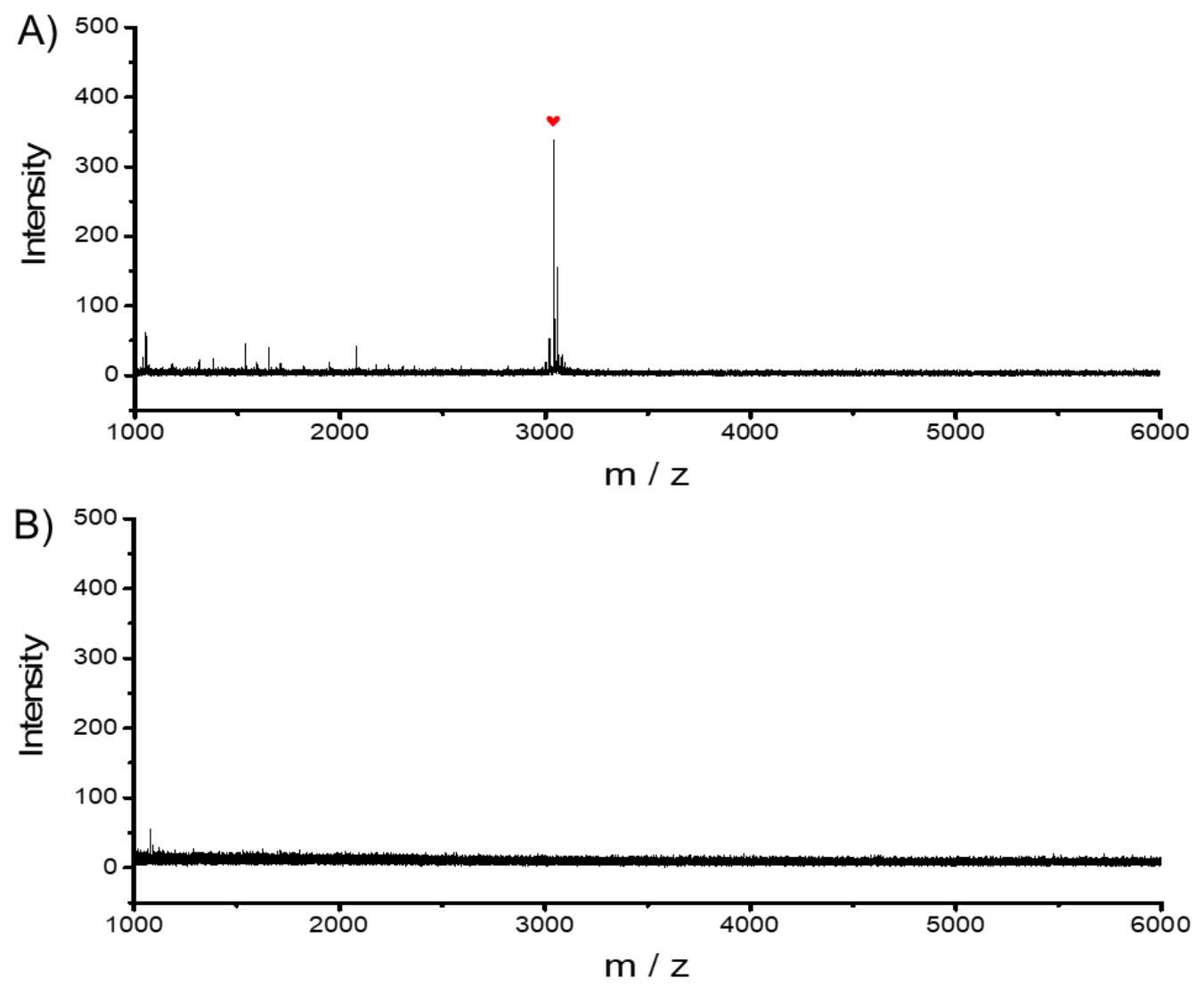

Figure S6. MALDI-TOF MS spectra for A) peptides from the tryptic digest of TRF extracted by peptide-imprinted MNPs and B) peptides from the tryptic digest of TRF extracted by non-imprinted MNPs (red heart symbol: the desired glycopeptide CGLVPVLAENYN\#K). 

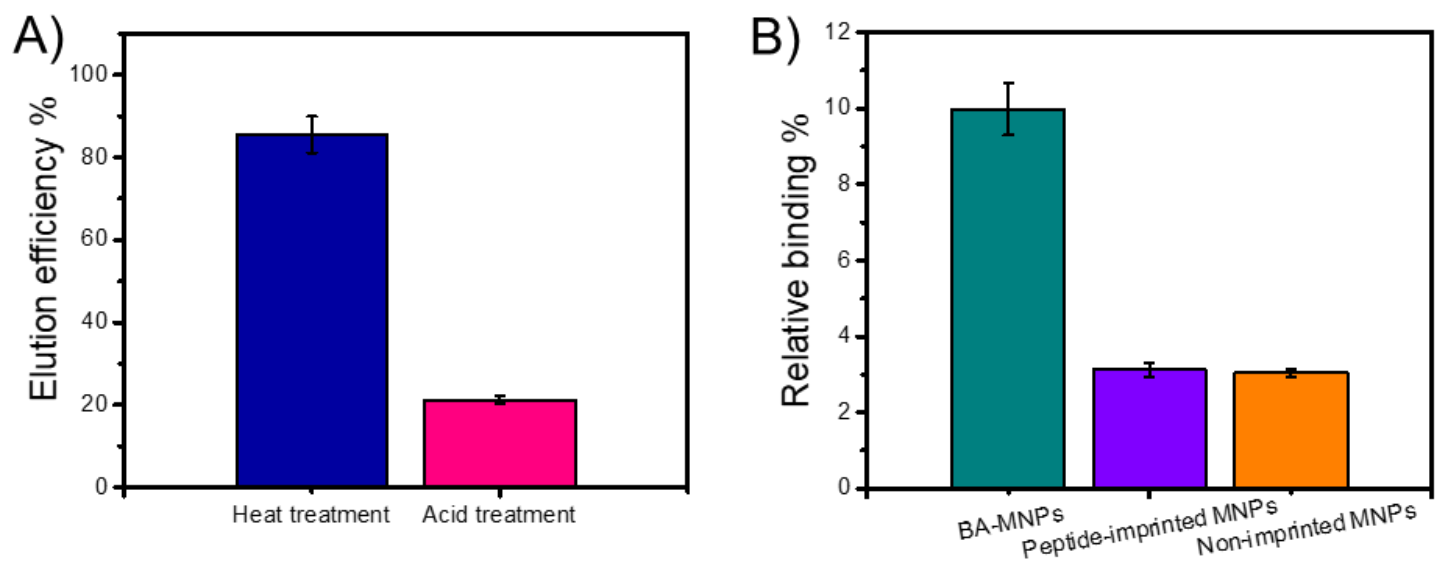

Figure S7. Characterization of A) elution efficiency under different treatment conditions, B) DNA nonspecific adsorption of BA-MNPs, peptide-imprinted MNPs and non-imprinted MNPs. Error bars represent standard deviations for three parallel measurements. 


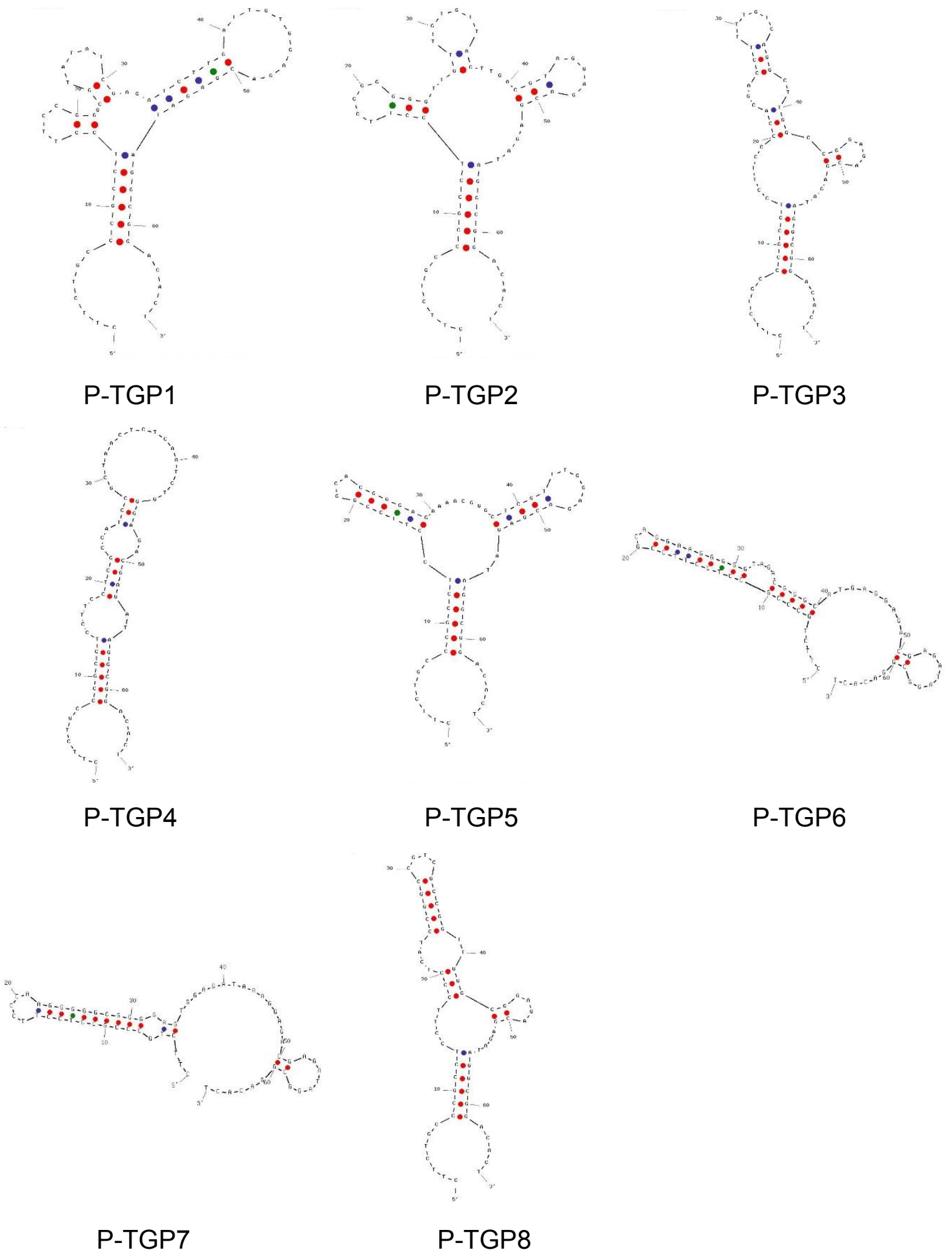

Figure S8. Predicted secondary structures of the primary aptamers. 

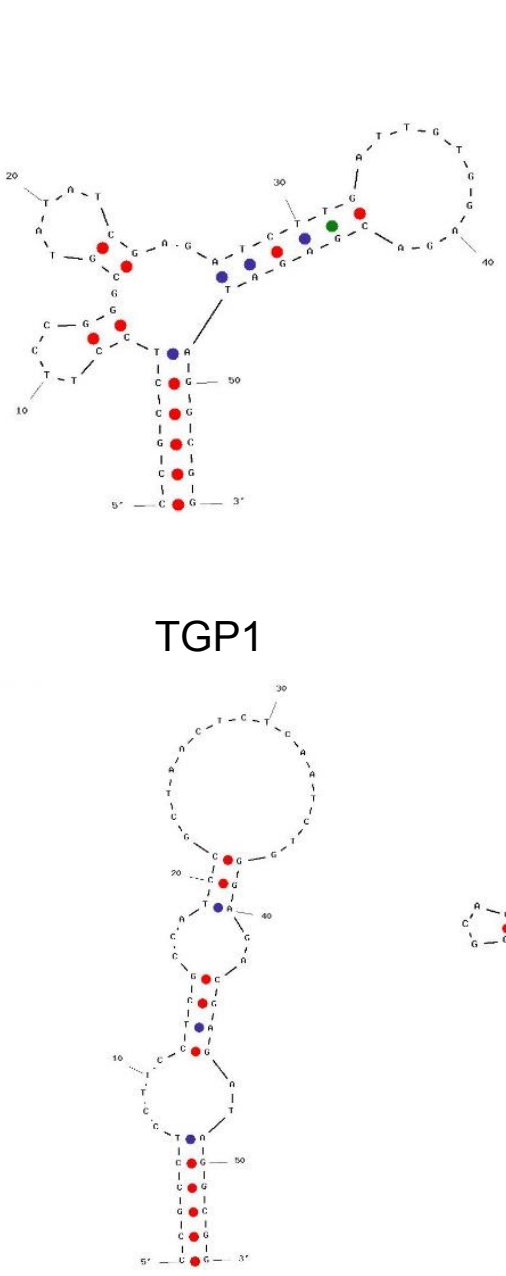

TGP4

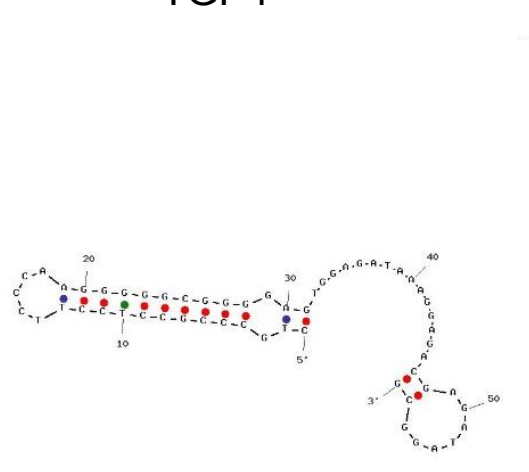

TGP7

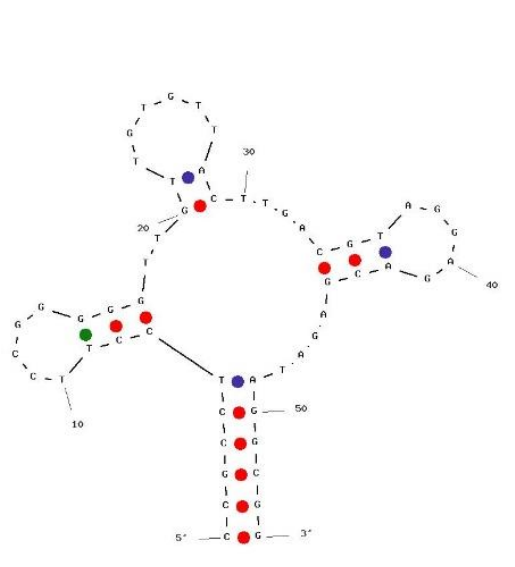

TGP2
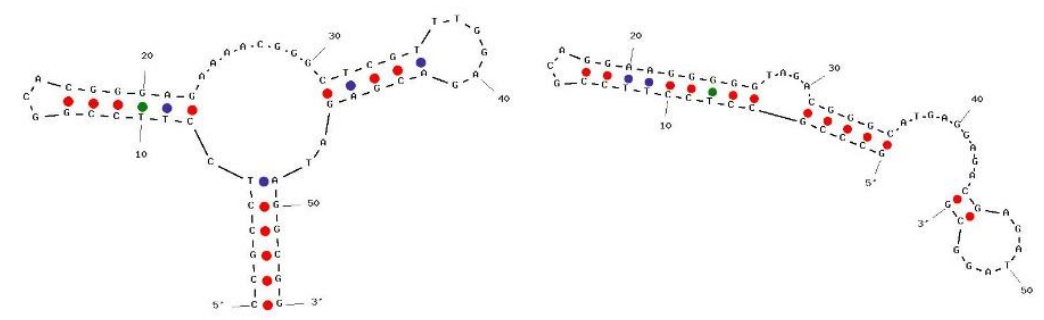

TGP5

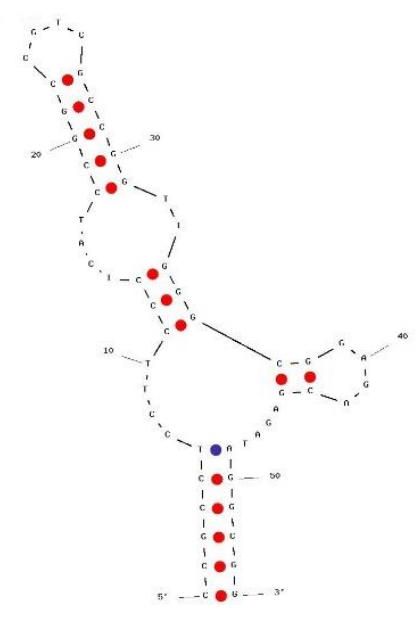

TGP8

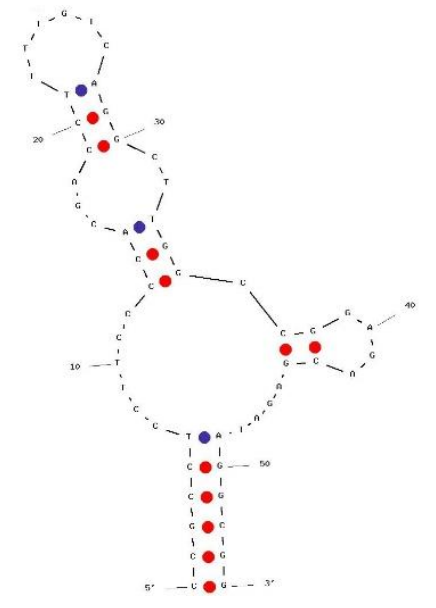

TGP3 

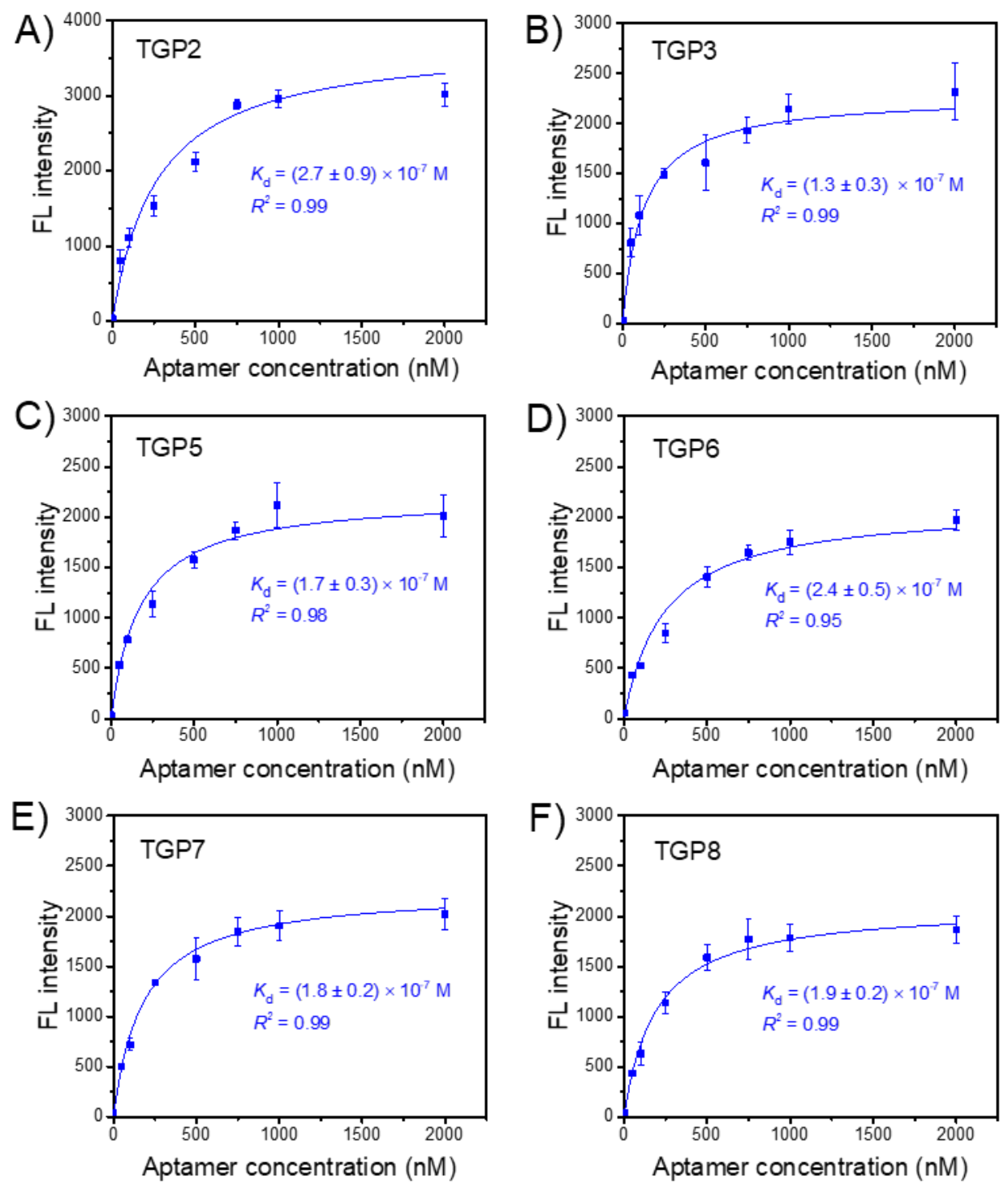

Figure S10. Binding affinity measurement of the candidate aptamers. A-F) TGP2, TGP3, TGP5-TGP8. Error bars represent standard deviations for three parallel measurements. 

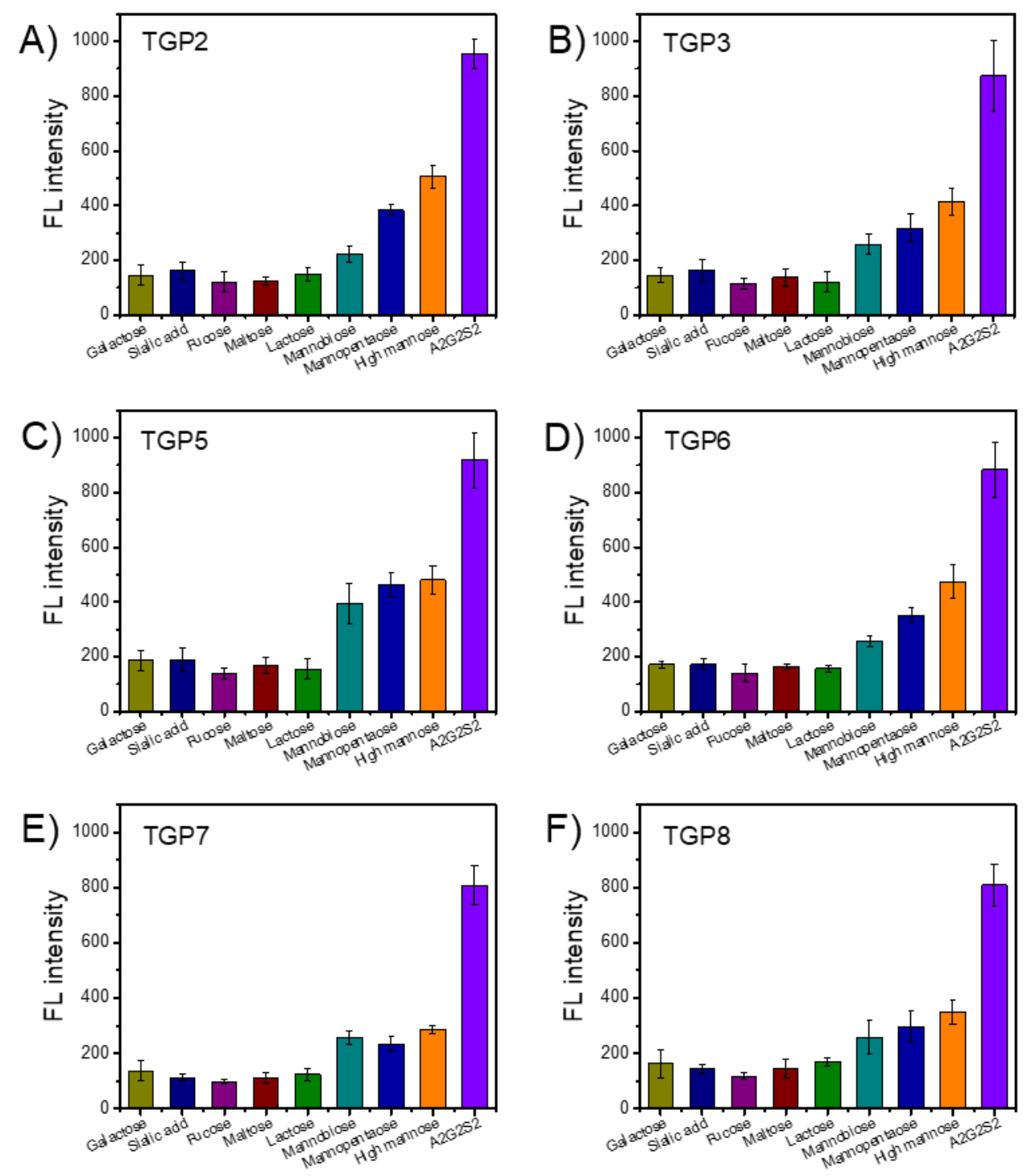

Figure S11. Specificity test of the candidate aptamers to different saccharides. A-F) TGP2, TGP3, TGP5-TGP8. Saccharides tested: galactose, sialic acid, fucose, maltose, lactose, mannobiose, mannopentaose, high mannose from RNase B and A2G2S2. Error bars represent standard deviations for three parallel measurements. 

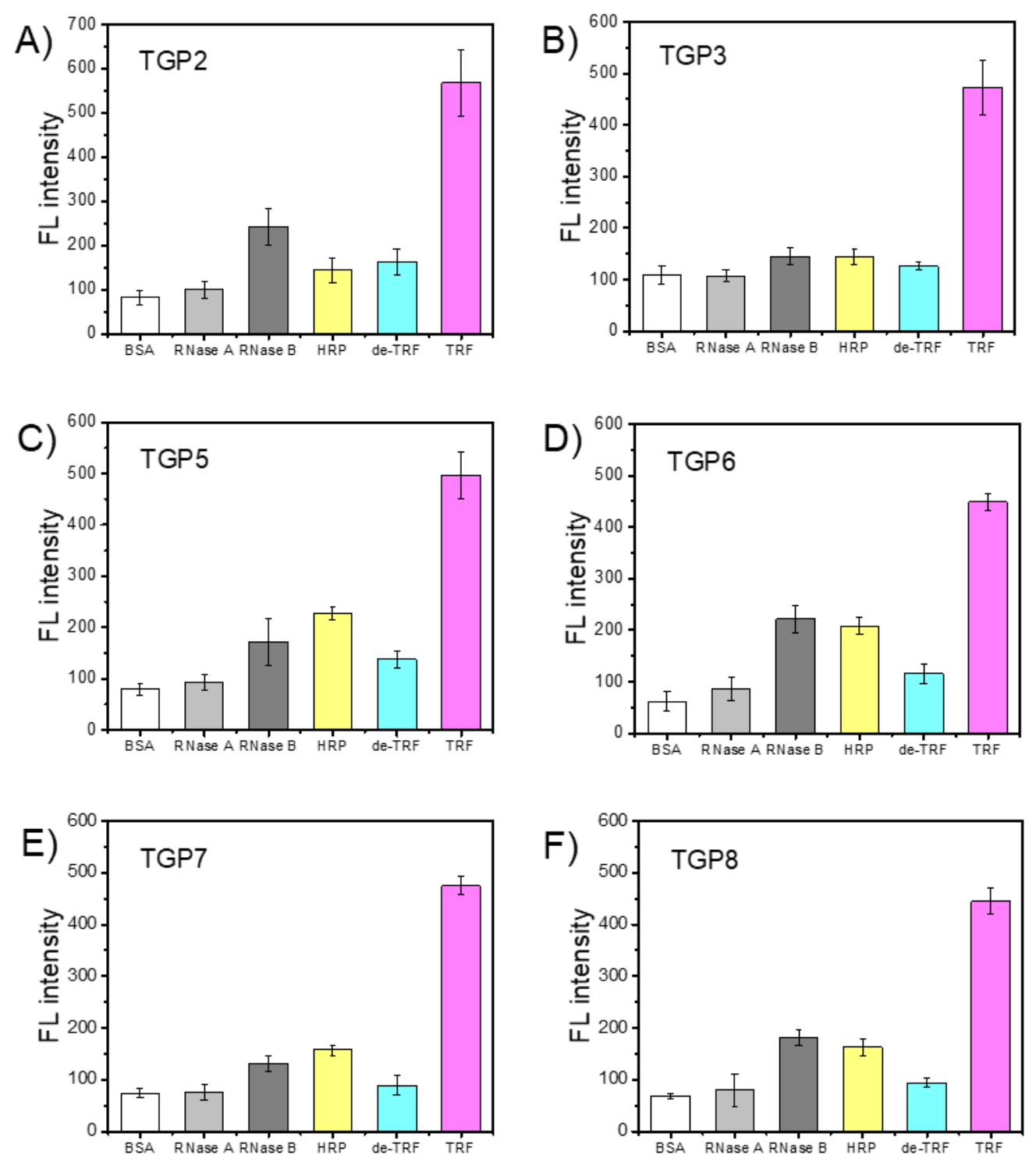

Figure S12. Specificity test of the candidate aptamers to different proteins. A-F) TGP2, TGP3, TGP5-TGP8. Proteins tested: BSA, RNase A, RNase B, HRP, deglycosylated TRF (de-TRF) and TRF. Error bars represent standard deviations for three parallel measurements. 

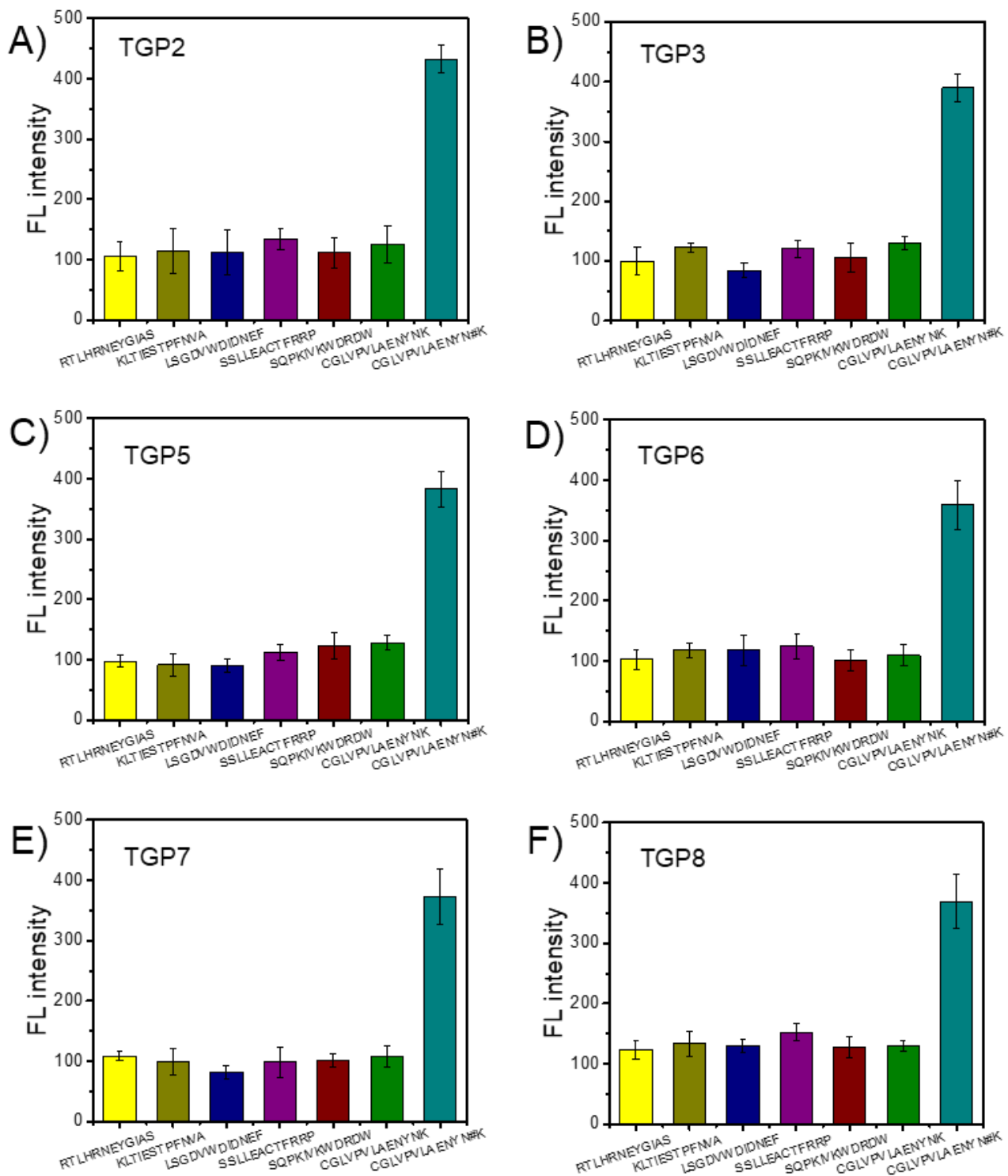

Figure S13. Specificity test of the candidate aptamers to different peptides. A-F) TGP2, TGP3, TGP5-TGP8. Peptides tested: RTLHRNEYGIAS, KLTIESTPFNVA, LSGDVWDIDNEF, SSLLEACTFRRP, SQPKIVKWDRDW, CGLVPVLAENYNK and CGLVPVLAENYN\#K. Error bars represent standard deviations for three parallel measurements. 


\section{Supplementary Tables}

Table S1. The modified and unmodified ssDNA sequences used in this study

\begin{tabular}{|c|c|}
\hline Description & Sequence (5' to 3') \\
\hline \multirow{2}{*}{ Initial FAM-ssDNA library } & FAM-CTTCTGCCCGCCTCCTTCC-(N25)- \\
\hline & GGAGACGAGATAGGCGGACACT \\
\hline FAM-Forward primer & FAM-CTTCTGCCCGCCTCCTTCC \\
\hline Forward primer & CTTCTGCCCGCCTCCTTCC \\
\hline \multirow[t]{2}{*}{ Reverse primer } & AGTGTCCGCCTATCTCGTCTCC \\
\hline & FAM- \\
\hline \multirow[t]{3}{*}{ FAM-TGP1 } & CCGCCTCCTTCCGGGCGTATATCGAGATCTTGATTGTG \\
\hline & GAGACGAGATAGGCGG \\
\hline & $\mathrm{NH}_{2}-\mathrm{C} 6-$ \\
\hline \multirow[t]{3}{*}{$\mathrm{NH}_{2}$-C6-TGP1 } & CCGCCTCCTTCCGGGCGTATATCGAGATCTTGATTGTG \\
\hline & GAGACGAGATAGGCGG \\
\hline & FAM- \\
\hline \multirow[t]{2}{*}{ FAM-Random } & CTTCTGCCCGCCTCCTTCCGACGAGTTTGATCCTTTTT \\
\hline & ATTATGGGAGACGAGATAGGCGGACACT \\
\hline
\end{tabular}


Table S2. The SELEX screening conditions used in this study

\begin{tabular}{cccc}
\hline Round & \multicolumn{2}{c}{ Incubation time (min) } & Number of washing \\
& Negative target & Positive target & steps \\
\hline 1 & 0 & 120 & 2 \\
2 & 0 & 120 & 2 \\
3 & 0 & 120 & 2 \\
4 & 60 & 120 & 3 \\
5 & 60 & 90 & 3 \\
6 & 60 & 90 & 3 \\
7 & 90 & 60 & 5 \\
8 & 90 & 60 & 5 \\
9 & 90 & 30 & 5 \\
10 & 90 & 30 & 5 \\
\hline
\end{tabular}


Table S3. The sequences of aptamer candidates

\begin{tabular}{|c|c|c|c|}
\hline Name & Sequence (5' to 3') & $\begin{array}{l}\text { Repeat } \\
\text { times }\end{array}$ & $\begin{array}{c}\mathrm{dG} \\
(\mathrm{kcal} / \mathrm{mol})\end{array}$ \\
\hline TGP1 & $\begin{array}{c}\text { CCGCCTCCTTCCGGGCGTATATCGAGATCTT } \\
\text { GATTGTGGAGACGAGATAGGCGG }\end{array}$ & 5 & -6.38 \\
\hline TGP2 & $\begin{array}{c}\text { CCGCCTCCTTCCGGGGGTTGTTGTGTTACTT } \\
\text { GACGTAGGAGACGAGATAGGCGG }\end{array}$ & 2 & -6.1 \\
\hline TGP3 & $\begin{array}{c}\text { CCGCCTCCTTCCCCACGACCTTTTGTCAGGC } \\
\text { TTGGCCGGAGACGAGATAGGCGG }\end{array}$ & 2 & -7.26 \\
\hline TGP4 & $\begin{array}{c}\text { CCGCCTCCTTCCTCGCCATCCGCTAACTCTC } \\
\text { AATCTGGGAGACGAGATAGGCGG }\end{array}$ & 2 & -7.63 \\
\hline TGP5 & $\begin{array}{c}\text { CCGCCTCCTTCCGGCACGGGAGAAAACGGG } \\
\text { CTCGTTTGGAGACGAGATAGGCGG }\end{array}$ & 1 & -13.58 \\
\hline TGP6 & $\begin{array}{c}\text { GCCCGCCTCCTTCCGCAGGAAGGGGGTAGA } \\
\text { CGGGCATGAGGAGACGAGATAGGCG }\end{array}$ & 1 & -14.13 \\
\hline TGP7 & $\begin{array}{c}\text { CTGCCCGCCTCCTTCCCAAGGGGGCGGGGA } \\
\text { GTGGAGATAAAGGAGACGAGATAGGCG }\end{array}$ & 1 & -13.74 \\
\hline TGP8 & $\begin{array}{c}\text { CCGCCTCCTTCCCTCATCCGGCCGTCGCCGG } \\
\text { TTGGGCGGAGACGAGATAGGCGG }\end{array}$ & 1 & -13.04 \\
\hline
\end{tabular}




\section{Supplementary References}

(1) Ferreira, C. S. M.; Matthews, C. S.; Missailidis, S. DNA aptamers that bind to MUC1 tumour marker: Design and characterization of MUC1-binding single-stranded DNA aptamers. Tumour Biol. 2006, 27, 289-301.

(2) Xing, R. R.; Ma, Y. Y.; Wang, Y. J.; Wen, Y. R.; Z. Liu. Specific recognition of proteins and peptides via controllable oriented surface imprinting of boronate affinity-anchored epitopes. Chem. Sci. 2019, 10, 1831-1835. 